\title{
Emotional Maturity of Tribal and Non-Tribal Pre - Adolescents: A Study of Gandhari Region in Nizamabad District
}

\author{
Deva Anjali ${ }^{1}$
}

\section{ABSTRACT}

Scheduled Tribes in the Gandhari area of Nizamabad District in Telangana State is interior area in the state. It is the most primitive area where tribal are living. The aim of this study is to investigate the effect of gender, community culture and type of school on emotional maturity of tribal and non-tribal pre-adolescents in Gandhari area. Present study sample comprised of 150 students. Their age range was 13 to 16 years. To assess emotional maturity, Emotional maturity scale. After careful examination of data results indicate that gender played a significant role in emotional maturity, females performed significantly better than the males, non-tribal children were better than their tribal counterparts and type of school also played significant role, where students of private schools had better emotional maturity than students of government schools.

Keywords: Community Culture, Emotional Maturity, Tribal, Pre Adolescents, Psychology, Education

Gandhari in Nizamabad District of Telangana State is well known as Tribal population area. It is the most primitive area where Lambadas are living. Apart from lambadas Koya, Gondu tribes also represent mixed combination of scheduled tribes. These are considered as a tribal community; apart from the tribal community population comprises non-tribal community also. This area is divided into tribal and non-tribal communities.

The most crucial phase in the life span of human being is adolescence, characterized by stress and storm, Granville Stanley Hall as well as Erik Homburger Erikson, identify the crisis. Basically period of adolescence can be classified into three parts'; preadolescence (age group of 13-16), middle adolescence (age group of 16-18) and late adolescence (age group of 19). In the youth the preadolescence is most crucial period. There are several psychological and physical differences between boys and girls become greater during pre-adolescence because of increase socialization pressures to conform to traditional masculine and feminine gender role (Lynch, 1991). Eve in the globalization era, the gender discrimination is playing a vital role and the treatment given to the female child is much different than the nourishment given to a male child.

\footnotetext{
${ }^{1}$ P.G Student, MSc Mathematics, Telangana University, Nizamabad, Telangana State, India. (C) 2015 I A Deva; licensee IJIP. This is an Open Access Research distributed under the terms of the Creative Commons Attribution License (http://creativecommons.org/licenses/by/2.0), which permits unrestricted use, distribution, and reproduction in any Medium, provided the original work is properly cited.
} 


\section{Emotional Maturity of Tribal and Non-Tribal Pre - Adolescents: A Study of Gandhari Region in Nizamabad District}

In this study the community culture, it is divided into two groups, first is tribal and another is non-tribal. Tribal people are original dwellers living from unrecorded time. They are financially substandard, uneducated at times and are less exposed and lifted to the modern world. Even in twenty-first century, the traditional Indian society is hierarchically organized; each stratum of this hierarchy is defined by the caste of people that constitute it. While the development of preadolescent, schools plays important role. In India, the schools run by the state government, differ in many respects from the private schools. Good schools impart education through well-trained teachers, use new teaching methods and teaching aids. Unfortunately, scarcity of these facilities is mostly found in the government schools. Ordinary or poor schools are generally lacks in these facilities. In India, the schools run by the Central and State governments separately. Apart of these schools many private organizations established educational institutions and providing education to the students. Especially private organizations run schools are putting more investment in the education and collecting the huge amount of the fee from the students. They are using new teaching methods and teaching aids. Unfortunately, till the government schools are far away for these kinds of facilities especially in rural areas. These schools are facing lots of obstacles in day to day life.

\section{BRIEF PROFILE OF STs IN TELANGANA STATE}

According to Scheduled Caste and Scheduled Tribes lists modification order 1956 and as a denotified Tribes in Telangana State (Comprises the districts of Adilabad, Nizamabad, Karimnagar, Medak, Hyderabad, Ranga Reddy, Mahaboobnagar, Nalgonda, Warangal and Khammam) as per the Indian constitution (Scheduled Tribe) Order 1950 the SC \& STs (amendment) Act 1976, the Telangana State Banjaras / Lambadas are recognized as Scheduled Tribes. The origin and history of Lambadas is very vague and ambiguous. There are many legends who explained their origin. They themselves claim that they are of Rajputs and Kshatriyas origin. Banjaras / Lambadas of Telangana State claim that they are from warrior race and have fought against the Mohammadans.

Many scholars opined that the word Banjara and Banjara (trader) have been derived from the profession trade. The name may have derived from Vanachara meaning Wanderer in jungles. The word Lambadi has been derived possibly from the word of Lamba meaning tall. The Banjara are very tall and handsome so they have been tall Lambada meaning "People who are tall". It is common phenomenon among Lambadas have to have their settlements called Thandas outside the main village. They prefer hilly areas for avoiding accumulations of mud which would be creating more problems to their cowherds. They try to raise their Thandas of the careful examination of their security, availability of water fertile land in that area and avoiding insecure atmosphere created by robbers and wild animals almost all Thandas in Telangana Districts are raised keeping all this facts in mind the Lambdas address each other GWAR and call NonLambadas as KWAR indicating their sense of entity every Thanda tenaciously maintain their culture and ethnic identity. The political life of Lambadas in Telangana districts reflects a paradoxical situation. They transformed retaining their political system and maintaining political 


\section{Emotional Maturity of Tribal and Non-Tribal Pre - Adolescents: A Study of Gandhari Region in Nizamabad District}

structure among them for very long. But with introduction of universal adult franchise in the country, there has been tremendous change and Banjaras, who were earlier excluded from participation in the traditional polity, have been given a definite role to play in modern democratic process. In Telangana districts there is no dispute between the new leadership based on hereditary and personal qualities. The traditional polity of Banjaras in Telangana observed the new values without losing their identity and tradition.

\section{EMOTIONAL MATURITY}

Emotional maturity is a psychological term used to indicate that a person responds to the situations or environment in a suitable manner. Maturity as defined by Finley (1996) is "the capacity of mind to endure an ability of an individual to respond to uncertainty, circumstances or environment in an appropriate manner". Emotional maturity means balanced personality. It means ability to govern disturbing emotion, show steadiness and endurance under pressure and be tolerant and free from neurotic tendency. Singh (1990) has reported that "Emotional maturity is not only the effective determinant of personality pattern but also helps to control the growth of an adolescent's development. A person who is able to keep his emotions under control, to brook delay and to suffer without self-pity might still be emotionally stunned". Chamberlain (1960) said that an 'emotionally matured' person is one whose emotional life is well under control.

Gender is a decisive factor in the adaptation of emotional maturity. Emotionally matured person express the emotion in the proper manner accepted by the society. Emotions are always influenced by gender differences. Society treats preadolescents as considering their gender, how to express the emotion in the social approved manner. For example, house work is reserved for the women and works outside of house are for the men. As girls spend more time with their family members than boys, so girls are more attach with the family. So naturally girls can express their emotions and understand others very well than their male counterparts. It seems that girls are more emotionally matured than boys (Boyd and Huffman, 1984; Chandanshive Ajit 2014).

Emotional development is likely to be affected by cultural contexts. Culture strongly affects the emotional maturity of pre-adolescents, lots of emotional volatility is happens in this period. Multiple factors influence a child's emotional expressivity, including innate differences, such as temperament (Kagan, 1994). Unhealthy cultural norms can affect the emotional maturity. In the low Socio Economic Status (SES) families, domestic violence is the routine for children. This affects the pre-adolescents emotional development. Also they do not have any liberty to express their views in front of parents and other respected people of the society. Sometimes preadolescents are right in their own side but only because of unhealthy social pressure they prove to be wrong. Such kind of situation happens in the deprived society and their cultural rules make emotionally unbalance to pre-adolescents, hence, such situations is a big obstacle for the healthy emotional development. Such kind of situation mostly found in deprived or tribal communities, whereas non-tribal communities are much conscious about their children emotional development. They always take care of each and every small need of their children. 


\section{Emotional Maturity of Tribal and Non-Tribal Pre - Adolescents: A Study of Gandhari Region in Nizamabad District}

This kind of difference between two communities may reflect in their behaviour. Hence, it is clearly seen that pre-adolescents from non-tribal group are found to be more emotionally matured as compare to their tribal counterparts (Sinha Vinita Kumari, 2014).

School is one the most important foundation pillars on which the child's personality develops. Surrounding of schools is the major aspect to develop the emotional development. Understanding the emotional maturity in the school arena is mostly depending on their teachers, schoolmates, environment, etc. in that case some schools identify their roles and provide the facilities to enhance emotional maturity of students. Generally, it is seen that private schools understand their responsibilities towards student's development and they exhibit better performance to enhance student's emotional maturity, but it is found that government schools provide fewer facilities than the private schools. Previous study also proved that students learning in government high school differ significantly from students learning in private school in emotional maturity. The mean value of private high school students is greater than the government high school students (Subramanian \& Veliappan, 2013).

\section{AIM OF THE STUDY}

The main aim of the undertaken study is to investigate the effect of Gender, Community Culture and Type of School on Emotional Maturity of Tribal and Non-Tribal Pre-Adolescents in Gandhari region in Nizamabad District of Telangana State.

This research work carried out in the between August-December 2014

\section{OBJECTIVES OF THE STUDY}

The main objective of the research study is;

- To evaluate the emotional maturity of Male and Female Pre Adolescents and find out the significant differ from each other on the measures of emotional maturity.

- To determine the emotional maturity of the Tribal and Non Tribal Pre Adolescents and find out the significant differ from each other.

- To evaluate the emotional maturity of the students in government schools and students in private schools and find out whether they significantly differ from each other.

\section{HYPOTHESIS OF THE STUDY}

In the measure the emotional maturity gender will play a significant role. Female will be surpassing to the male in case of emotional maturity.

Tribal and Non-Tribal Pre Adolescents will differ significantly on the measure of emotional maturity. Non Tribal Pre Adolescents will be more emotionally mature than their tribal counterparts.

Type of schooling will play significant role on the measure of emotional maturity. Students in private schools will perform better than students in government schools on a certain measure of emotional maturity. 


\section{METHODOLOGY}

\section{Research Design}

A 2x2x2 factorial design was used. Gender, Community Culture and Type of School were treated as independent variables and Emotional Maturity was considered as dependent variable.

\section{Sampling}

As regarding to the aim, sample for the study, both Tribal and Non-Tribal pre-adolescents were selected from various government and private schools in the Gandhari region of Nizamabad District. Their age range was 13 to 16 years. The effective sample was comprised of 150 subjects only.

\section{Statistical Analysis of the Data}

First, means and Standard Deviation Values (SDs) were computed and then Three Way ANOVA was used. On the basis of the results of the study following conclusions were drawn.

\section{DISCUSSION}

Emotional maturity of the subjects was measured with the help of standardized scale. After careful scoring of the test, Mean and Standard Deviation values for all eight classified groups were computed.

Table I: Mean and Standard Deviation Values of Eight Classified Groups

\begin{tabular}{|l|l|l|l|l|l|l|l|l|}
\hline & A1B1C1 & A1B1C1 & A1B2C1 & A1B2C2 & A2B1C1 & A2B1C2 & A2B2C1 & A2B2C2 \\
\hline M & 115.3 & 113.2 & 119.75 & 103.85 & 107.85 & 84.55 & 99.05 & 80.57 \\
\hline SD & 25.81 & 20.97 & 23.84 & 26.25 & 42.26 & 25.01 & 14.54 & 19.46 \\
\hline
\end{tabular}

The categorization is as follows

A1=Male, A2= Female, B1=Tribal, B2= Non-Tribal, C1=Government School, C2= Private school

After keen examination of means and standard deviations reveals that there are sufficient large variations in the means obtained by eight classified groups. On emotional maturity scale low score denotes better emotional maturity considering this criterion it is observed that group A2B2C2 exhibited relatively superior emotional maturity compared to the remaining seven classified groups. This group obtained Means of 80.57 and Standard Deviation is 19.46. Among eight classified groups the highest Mean value was obtained by group A1B2C1 (Mean=119.75, $\mathrm{SD}=23.84$ ), whereas the difference between lowest and highest mean value is large so it seems that the group might differ sufficient each other on emotional maturity measure. There is a large variation in standard deviations of all the eight classified groups. The group A2B2C1 obtained smallest SD value whereas in case of A2B1C1 is the highest. Highest SD value indicates more variations in test scores. However, only on the measure of Mean and Standard Deviations interference cannot be drawn. Considering these variations in the obtained Mean and Standard 


\section{Emotional Maturity of Tribal and Non-Tribal Pre - Adolescents: A Study of Gandhari Region in Nizamabad District}

Deviation values the data were treated by three-way ANOVA, so as reveal more meaningful conclusions. Hence, further the data of eight classified groups were treated.

Table II: The complete summery of the three way analysis (ANOVA)

\begin{tabular}{|l|l|l|l|l|}
\hline $\begin{array}{l}\text { Source of } \\
\text { Variation }\end{array}$ & S.S & df & M.S & F \\
\hline A & 32441.51 & 1 & 32441.51 & $48.25^{* *}$ \\
\hline B & 1462.04 & 1 & 1462.04 & 2.17 \\
\hline C & 17582.44 & 1 & 17582.44 & $26.15^{* *}$ \\
\hline AxB & 273.8 & 1 & 273.8 & 0.40 \\
\hline AxC & 2691.2 & 1 & 2691.2 & $4.00^{*}$ \\
\hline BxC & 446.51 & 1 & 446.51 & 0.66 \\
\hline AxBxC & 1629.01 & 1 & 1629.01 & 2.42 \\
\hline WITHIN & 209744.5 & 312 & 672.25 & \\
\hline TOTAL & 266271.01 & & & \\
\hline
\end{tabular}

$\mathrm{df}=1$ and $312,0.01=6.66^{* *}, 0.05=3.85^{*}$

In the entire research, the main effect A represents the factors of gender varied at two levels, namely males and females. Main effect A obtained significant mean square value. ( $F=48.25$, $d f$ $=1 \& 312, \mathrm{p}<0.01$ ) this significant $\mathrm{F}$ values tells us that with regards to emotional maturity males and females differ significantly from each other's it means that Means obtained by the two broad groups differ so largely that the difference cannot be attributed to the factor of chance only. To find out whether the males have significantly superior emotional maturity or the females, mean value for two broad groups were computed. The broad group of males obtained a mean 113.02, whereas the broad group of females obtained a mean of 92.87. The difference in this two means is so large. That is cannot be attributed to the factor of chance only. On the basis of result it could be concluded that the females had significantly better emotional maturity than the males. Main effect B represent factor of community culture. Two types of culture namely tribal and non-tribal were included in the study. Main effect B obtained on F values of 2.17, which for $1 \& 312 \mathrm{df}$ (degrees of freedom) is no significant at $0.01 \& 0.05$ levels. It could be concluded that B factor is not the conducive variable in Emotional maturity. In order to reveal which group performs better on emotional maturity, mean values were computed for the two broad groups. The obtained mean value for tribal is 105.09 and for non-tribal is 100.80 . It indicates that the difference between these scores is not quite high, though nontribal performed better as compared to tribal. This difference can be attributed to the factor of chance only. On the basis of this it can be concluded that community culture is not an influencing factor in emotional maturity. 


\section{Emotional Maturity of Tribal and Non-Tribal Pre - Adolescents: A Study of Gandhari Region in Nizamabad District}

Type of school which (which is taken as third factor) represented by main effect C. which was also varied at two levels namely Government schools and Private schools. From the summery of the ANOVA it is seem that type of school also brought out significant results. Main effect $\mathrm{C}$ yielded significant results $(\mathrm{F}=26.15 ; \mathrm{df}=1 \& 312$; $\mathrm{p} 0.05)$ obviously culture and type of school functioned independently while influencing the development of emotional maturity. While influencing the development of emotional maturity even A x B x C was also non-significant $(\mathrm{F}=2.42, \mathrm{df}=1 \& 312, \mathrm{p}>0.05)$ this significant $\mathrm{F}$ values clearly tells us that government schools and private schools differ significantly from each other on emotional maturity. To find out whether the students in government schools have better emotional maturity or the students in private schools, eight classified groups were clustered into two broad groups only on the basis of type of school and for these broad groups mean values were computed. The broad group of students in government school obtained mean value of 110.35, whereas the broad group of students in private schools obtained a mean of 95.54. The difference in these two groups is very high. On the basis of these results it could be concluded that students in private schools had better emotional maturity than students in government schools.

Interaction A x B obtained an F values of 0.40 which for 1 \& $312 \mathrm{df}$ is non-significant. Interaction effect between gender and type of school A x C is significant at 0.05 level $(\mathrm{F}=4.00$, $\mathrm{df}=1 \& 312, \mathrm{p} 0.05$ ) obviously culture and type of school functioned independently while influencing the development of emotional maturity. While influencing the development of emotional maturity even A x B x C was also non-significant ( $F=2.42$, $d f=1 \& 312, p>0.05)$ this significant three factor interaction clearly tells us that the three independent variable function is not collaborated with each other.

\section{CONCLUSION}

The statistical analysis and interpretation shows that the gender playing a significant role on the effect of the emotional maturity of pre adolescents. Female respondents were far better than male. On the measure of emotional maturity females were performed significantly better than the males. The result shows that on the measure of emotional maturity non-tribal performed better than tribal community. At the same time type of school was played significant role in the measure of emotional maturity. On the measure of emotional maturity students in private schools performed significantly better than students in government schools.

\section{REFERENCES}

Aleen K, Sheema P (2005). Emotional Stability Among College Youth. Journal of Indian Academy of Applied Psychology, Volume: 31, Issue: 2: 99-102, ISSN: 0019-4247.

Athanimath JS, Yenagi G (2011). Social Maturity and Depression Levels Among II PUC Science Students. Karnataka Journal of Agricultural Sciences, Volume: 24, 510-512, ISSN-0972-1061..

Boyd NR, Huffman WJ (1984). The Relationship Between Emotional Maturity and Drinkingand - Driving Involvement among Young Adults, J. Saf. Res., 15(1): 1-6. 


\section{Emotional Maturity of Tribal and Non-Tribal Pre - Adolescents: A Study of Gandhari Region in Nizamabad District}

Chamberlain VC (1960). Adolescence to Maturity, London: The Badley Head. Drinking - and Driving Involvement among Young Adults. J. Saf. Res., 15(1): 1-6.

Chandanshive Ajit (2014). Study of Emotional Maturity and Self Confidence of Adolescents, Indian Streams Research Journal, Volume-4, Issue-8, ISSN: 2230-7850

Finley J (1996). Behaviour and Development from 5 to 12. New York: Harper and Row.

Kegan, J. (1965). The Child Perception of Parent. Journal of Abnormal and Social Psychology, Volume 53, Issue 2; ISSN: 0021-843X.

Khule O Aakash (2015). A Study of Emotional Maturity of Tribal and Non Tribal and Non Tribal Pre Adolescents in Melghat Region, International Journal of Educational and Psychological Research, Volume: 4, Issue: 2, ISSN: 2279-0179,

Laal Banoth (2013). Community Organisation of Telangana Lambadas: Transition Gwar Pancyat to Modern Political Institution, International Journal of Political Science, Law and International Relations (IJPSLIR), Volume: 3. Issue: 4, ISSN: 2278-8832,

Lynch, M. E. (1991). Gender Intensification, In R.M. Lerner, A.C. Petersen, \& J. Brooks-Gunn (Eds.), Encyclopaedia of adolescence (Vol. I), New York: Garland.

Singh, P.Y. and Bhargava, M. (1990). Emotional Maturity Scale, Agra: National Psychological Corporation. Sinha.

Subramanian N. \& Veliappan A.(2013). A Study on Emotional Maturity of High School Students. Indian Journal of Applied Research, Volume: 3, Issue: 11 Nov 2013 ISSN: 2249-555X.

Vinita Kumari (2014). A Study of Emotional Maturity Among Tribal and Non-Tribal Adolescent Girls. Indian Journal of Applied Research, Volume: 4, Issue: 7, July 2014, ISSN - 2249$555 X$.

\section{ACKNOWLEDGEMENTS}

I am very much thankful to Dr. G. Chandra Shekhar, Chairman, Board of Studies, Dept. of Mass Communication, Telangana University, India who assesional Maturity, Emotional Maturity scale. The test comprised of 48 items. It measured Emotional Stability, Emotional Progression, Social Adjustment, Personality Integration and Independence as Dimensions of Emotional Maturity. 